Pacific Journal of Mathematics

ON THE GENERALIZED CALKIN ALGEBRA

I AND ALBERt Jonathan KIEIN 


\title{
ON THE GENERALIZED CALKIN ALGEBRA
}

\section{J. J. BUONI AND A. KLEIN}

\begin{abstract}
A bounded linear operation $T: X \rightarrow Y$ between Banach spaces is said to be weakly compact if it takes bounded sequences onto sequences which have a weakly convergent subsequence. Let $W[X, Y]$ denote the weakly compact operators from $X$ to $Y, B[X, Y]$, the bounded operators and $K[X, Y]$, the compact operators. Now $W[X, Y]$ forms a closed subalgebra of $B[X, Y]$ and for $X=Y, W[X, X]$ is a closed (in the uniform topology) two-sided ideal of $B[X, X]$. The purpose of this note is to construct a faithful representation of the Generalized Calkin Algebra $B[X, X] / K[X$, $X]$, which parallels a similar representation of $B[X, X] /$ $K[X, X]$ in Buoni, Harte and Wickstead, "Upper and lower Fredholm spectra"'.
\end{abstract}

This construction in obtained is $\S 1$ and some consequences in $\S 2$ with regards to operators $T \in B[X, Y]$ with a reflexive null space, $N(T)$, and closed range, $R(T)$. Operators of this type have been studied by Yang. Throughout this note, the weak closure of a set $S$ in $X$ will be denoted by $\bar{S}^{w}$.

1. If $X$ is a complex Banach space then let $l_{\infty}(X)$ denote the Banach space obtained from the space of all bounded sequences $x=\left(x_{n}\right)$ in $X$ by imposing term-by-term linear combinations and the supremum norm $\|x\|_{\infty}=\sup _{n}\left\|x_{n}\right\|$.

Definition 1. If $X$ is a Banach space then denote $m(X)=$ $\left\{\left(x_{n}\right) \in l_{\infty}(X) \mid\left(\bar{x}_{n}\right)^{w}\right.$ is weak-compact in $\left.X\right\}$.

Lemma 1. If $X$ is a Banach space then the following hold.

(1) $m(X)$ is a subspace of $l_{\infty}(X)$.

(2) a sequence $x=\left(x_{n}\right)$ is in $m(X)$ iff every subsequence of $\left(x_{n}\right)$ has a weak convergent subsequence.

Proof. (1) is clear and (2) is an immediate application of the Eberlein-Smulian theorem [2, p. 430] which states that for a subset $A$ of $X$ then $\bar{A}^{w}$ is weak-compact iff every sequence in $A$ has a weakly convergent subsequence.

Let $\overline{m(X)}$ denote the norm closure of $m(X)$ in $l_{\infty}(X)$.

LEMmA 2. Every subsequence of an element in $m(X)(\overline{m(X)})$ is 
also in $m(X)(\overline{m(X}))$.

Proof. This follows immediately from Lemma 1 part 2.

TheoRem 3. If $X$ is a Banach space then $m(X)$ is a closed subspace of $l_{\infty}(X)$.

Proof. Let $x=\left(x_{n}\right) \in \overline{m(X)}$, i.e., the closure of $m(X)$ in $l_{\infty}(X)$. It shall first be shown that $\left(x_{n}\right)$ has a weak-Cauchy subsequence and then that this sequence converges to an element in $X$. Thus there exists $y_{1}=\left(y_{1, n}\right) \in m(X)$ and $\left(x_{1, n}\right)$, a subsequence of $x$ such that $y_{1, n} \stackrel{w}{\rightarrow} y_{1}$ (converges weakly to $\left.y_{1}\right)$ and $\left\|\left(x_{1, n}\right)-\left(y_{1, n}\right)\right\|_{\infty}<1$. Now assume for $1 \leqq l \leqq j-1$, that we have $\left(x_{l, n}\right)$ and $\left(y_{l, n}\right)$ which satisfy the following:

(1) $\left(x_{l, n}\right)$ is a subsequence of $\left(x_{l-1, n}\right)$,

(2) $y_{l, n} \stackrel{w}{\rightarrow} y_{l}$,

(3) $\left\|\left(x_{l, n}\right)-\left(y_{l, n}\right)\right\|_{\infty}<1 / l$.

Then since $\left(x_{j-1, n}\right) \in m(X)$, there exists a subsequence $\left(x_{j, n}\right)$ of $\left(x_{j-1, n}\right)$ and there exists $\left(y_{j, n}\right) \in \overline{m(X)}$ such that $y_{j, n} \stackrel{w}{\rightarrow} y_{j}$ and $\left\|\left(x_{j, n}\right)-\left(y_{j, n}\right)\right\|_{\infty}<$ $1 / j$. So by induction, for all $j$, there exist sequences satisfying (1.1). Now fix $j$ and $f \in X^{*}$ (the conjugate of $X$ ). We claim that there exists $M$ such that for all $n$ and $m \geqq M$ that

$$
\left|f\left(x_{j, n}\right)-f\left(x_{j, m}\right)\right| \leqq 4\|f\| / j \text {. }
$$

To see this, recall that $y_{j, n} \stackrel{w}{\rightarrow} y_{j}$, then there exists $M$ such that

$$
\left|f\left(y_{j, n}\right)-f\left(y_{j}\right)\right| \leqq\|f\| / j \text { for all } n>M .
$$

Now for all $n, m \geqq M$,

$$
\begin{aligned}
& \left|f\left(x_{j, n}\right)-f\left(x_{j, m}\right)\right| \leqq\left|f\left(x_{j, n}\right)-f\left(y_{j, n}\right)\right|+\left|f\left(y_{j, n}\right)-f\left(y_{j}\right)\right| \\
& \quad+\left|f\left(y_{j}\right)-f\left(y_{j, m}\right)\right|+\left|f\left(y_{j, m}\right)-f\left(x_{j, m}\right)\right|
\end{aligned}
$$

Now by applying (1.1) and (1.3) to (1.4) yields (1.2). We shall now show that $\left(x_{i, i}\right)$ is a weak-Cauchy sequence. Given $f \varepsilon X^{*}$ and $\varepsilon>0$, select $j$ such that $4\|f\| / j<\varepsilon$. Then by (1.2) there exists $M_{0}$ such that for all $m$ and $n \geqq M_{0}$

$$
\left|f\left(x_{j, n}\right)-f\left(x_{j, m}\right)\right| \leqq 4\|f\| / j .
$$

Set $M=\max \left(j, M_{0}\right)$. For $m$ and $n \geqq M$, because $\left(x_{n, k}\right)$ and $\left(x_{m, k}\right)$ are subsequences of $\left(x_{j, k}\right)$, then $\left|f\left(x_{n, n}\right)-f\left(x_{m, m}\right)\right| \leqq 4\|f\| / j<\varepsilon$.

It remains to show that any weakly-Cauchy subsequence of 
$\left(x_{n}\right) \in \overline{m(X)}$ converges weakly. To this end, let $\left(x_{n}\right) \in \overline{m(X)}$ be a weakly-Cauchy sequence.

Define $F: X^{*} \rightarrow C$ by $F(f)=\lim _{n \rightarrow \infty} f\left(x_{n}\right)$. Since $|F(f)| \leqq\|f\|$ $\sup _{n}\left\|x_{n}\right\|$, then $F \in X^{* *}$. Now let $\varepsilon>0$, it shall be shown that there exists $y \in X$ such that $\left\|F-y^{* *}\right\|<\varepsilon$ where $y^{* *}$ is the canonical image of $y$ in $X^{* *}$. To see this, select $\left(y_{n}\right) \in m(X)$ such that $\left\|\left(x_{n}\right)-\left(y_{n}\right)\right\|<\varepsilon / 3$ and select a subsequence $\left(y_{n_{k}}\right)$ of $\left(y_{n}\right)$ such that $y_{n_{k}} \stackrel{w}{\rightarrow} y$. Select $f \in X^{*}$ such that $\|f\| \leqq 1$. For $k$ sufficiently large, $\left|f\left(y_{n_{k}}\right)-f(y)\right|<\varepsilon / 3$ and $\left|f\left(x_{n_{k}}\right)-F(f)\right|<\varepsilon / 3$. Thus, for $k$ sufficiently large,

$$
\begin{aligned}
& \left|F(f)-y^{* *}(f)\right| \leqq\left|F(f)-f\left(x_{n_{k}}\right)\right|+\left|f\left(x_{n_{k}}\right)-f\left(y_{n_{k}}\right)\right| \\
& \quad+\left|f\left(y_{n_{k}}\right)-f(y)\right| \leqq \frac{\varepsilon}{3}+\|f\|\left\|x_{n_{k}}-y_{n_{k}}\right\|+\frac{\varepsilon}{3}<\varepsilon .
\end{aligned}
$$

Thus, $F$ is in the norm closure of the canonical image of $X$ in $X^{* *}$. This image is norm closed; therefore, there exists $x \in X$ such that $F$ is the canonical image of $x$. Thus, $m(X)=\overline{m(X)}$ which proves our theorem.

2. Now for $T \in B[X, Y]$ we have

Lemma 4. (1) If $T \in B[X, Y]$, then $T$ sends $m(X)$ to $m(Y)$.

(2) $T$ is weakly-compact iff $T$ maps $l_{\infty}(X)$ into $m(Y)$.

Proof. Clear.

Now for $T \in B[X, Y]$, let $P(T)$ be the induced operator from $l_{\infty}(X) / m(X) \rightarrow l_{\infty}(Y) / m(Y)$. Denote by $\mathscr{P}(X)$ the quotient $l_{\infty}(X) /$ $m(X)$. Then $W \in W[X, Y]$ iff $P(W)=0$. Therefore we have the following theorem.

THEOREM 5. $B[\mathscr{S}(X), \mathscr{P}(X)]$ contains a faithful representation of $B[X, X] / W[X, X]$.

THEOREM 6. Let $T \in B[X, Y]$.

(1) If $N(T)$ is a reflexive subspace and is complemented in $X$ and if $R(T)$ is closed then $P(T)$ is one-to-one.

(2) If $P(T)$ is one-to-one, then $N(T)$ is a reflexive subspace of $X$.

Proof. To see (1) let $N(T)$ be a complemented reflexive subspace, then there exists a closed subspace $M$ such that $X=N(T) \oplus$ $M$. Since $R(T)$ is closed, then $T \mid M(T$ restricted to $M)$ is an isomor- 
phism. Now let us assume that there exists a sequence $\left(x_{n}\right)$ in $l_{\infty}(X)$ such that $P(T)\left(x_{n}+m(X)\right)=\left(T x_{n}\right)+m(Y)=m(Y)$.

Let $x_{n}=k_{n}+z_{n}$ where $x_{n} \in N(T)$ and $z_{n} \in M$. Since there exist bounded projections onto $N(T)$ and $M$ then $\left(k_{n}\right)$ and $\left(z_{n}\right)$ are in $l_{\infty}(X)$. Now $\left(T x_{n}\right)$ has a weakly-convergent subsequence, say $\left(T x_{n_{j}}\right)$. Thus $\left(T z_{n_{j}}\right.$ ) converges weakly and since $R(T)=T(M)$ is closed then $T z_{n_{j}} \stackrel{w}{\rightarrow} T z$ for some $z \in X$. Since $T$ is invertible when restricted to $M$, thus, $z_{n_{j}} \stackrel{w}{\rightarrow} z$. Since $N(T)$ is a reflexive subspace, some subsequence of $\left(k_{n_{j}}\right)$ converges weakly; $\left(x_{n}\right)$ has a weakly convergent subsequence and $\left(x_{n}\right) \in m(X)$.

To see (2), we assume that $N(T)$ is not reflexive, then there exists a bounded sequence $\left(x_{n}\right)$ in $N(T)$ with no convergent subsequence. Hence, $\left(x_{n}\right) \notin m(X)$ while $\left(T x_{n}\right) \in m(Y)$; contradicting that $P(T)$ is one-to-one.

Acknowledgments. The authors would like to thank Professor Charles Byrne for discussions with regards to this problem.

\section{REFERENCES}

1. J. J. Buoni, R. E. Harte and A. W. Wickstead, Upper and lower Fredholm spectra, Proc. Amer. Math. Soc., 66 (1977), 309-314.

2. N. Dunford and J. T. Schwartz, Linear Operators, Part 1, Interscience Publishers Inc., New York 1958.

3. S. Goldberg, Unbounded Linear Operators, McGraw-Hill Book Co., New York 1966.

4. K. W. Yang, The generalized Fredholm operators, Trans Amer. Math. Soc., 216 (1976), 313-326.

Received April 5, 1978 and in revised form July 14, 1978.

Youngstown State UNIVERSITY

YoUNGSTOWN, OH 44555 


\section{PACIFIC JOURNAL OF MATHEMATICS}

\section{EDITORS}

RICHARD ARENS (Managing Editor)

University of California

Los Angeles, California 90024

C. W. CURTIS

University of Oregon

Eugene, OR 97403

C. C. MOORE

University of California

Berkeley, CA 94720
J. DugundjI

Department of Mathematics University of Southern Californı Los Angeles, California 90007

R. Finn and J. Milgram Stanford University Stanford, California 94305

ASSOCIATE EDITORS

E. F. BECKENBACH

B. H. NeUmanN

F. WOLF

K. YoSHIDA

\section{SUPPORTING INSTITUTIONS}

UNIVERSITY OF BRITISH COLUMBIA CALIFORNIA INSTITUTE OF TECHNOLOGY

UNIVERSITY OF CALIFORNIA

MONTANA STATE UNIVERSITY

UNIVERSITY OF NEVADA, RENO

NEW MEXICO STATE UNIVERSITY

OREGON STATE UNIVERSITY

UNIVERSITY OF OREGON
UNIVERSITY OF SOUTHERN CALIFORNIA

STANFORD UNIVERSITY

UNIVERSITY OF HAWAII

UNIVERSITY OF TOKYO

UNIVERSITY OF UTAH

WASHINGTON STATE UNIVERSITY

UNIVERSITY OF WASHINGTON 


\section{Pacific Journal of Mathematics}

\section{Vol. 80, No. $1 \quad$ September, 1979}

Jeroen Bruijning and Jun-iti Nagata, A characterization of covering dimension by

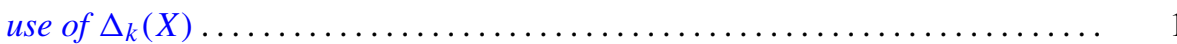

John J. Buoni and Albert Jonathan Klein, On the generalized Calkin algebra ...... 9

Thomas Ashland Chapman, Homotopy conditions which detect simple homotopy

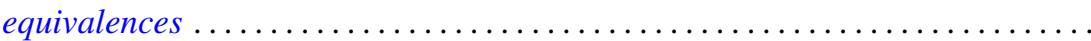

John Albert Chatfield, Solution for an integral equation with continuous interval

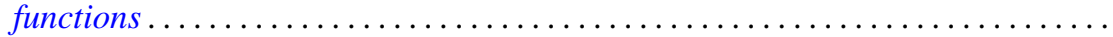

Ajit Kaur Chilana and Ajay Kumar, Spectral synthesis in Segal algebras on

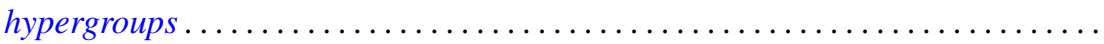

Lung O. Chung, Jiang Luh and Anthony N. Richoux, Derivations and

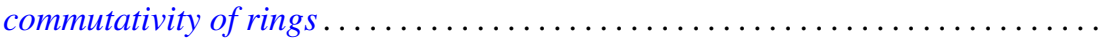

Michael George Cowling and Paul Rodway, Restrictions of certain function spaces to closed subgroups of locally compact groups .....................

David Dixon, The fundamental divisor of normal double points of surfaces........

Hans Georg Feichtinger, Colin C. Graham and Eric Howard Lakien,

Nonfactorization in commutative, weakly selfadjoint Banach algebras . . . . . . .

Michael Freedman, Cancelling 1-handles and some topological imbeddings ....... .

Frank E., III Gerth, The Iwasawa invariant $\mu$ for quadratic fields . . . . . . . . . . . . . .

Maurice Gilmore, Three-dimensional open books constructed from the identity

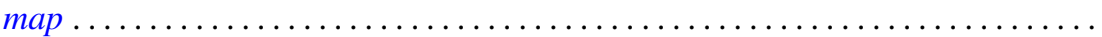

Stanley P. Gudder, A Radon-Nikodým theorem for $*$-algebras .

Peter Wamer Harley, III and George Frank McNulty, When is a point Borel? .

Charles Henry Heiberg, Fourier series with bounded convolution powers . .

Rebecca A. Herb, Characters of averaged discrete series on semisimple real Lie

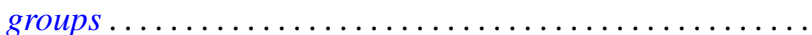

Hideo Imai, On singular indices of rotation free densities . .

Sushil Jajodia, On 2-dimensional CW-complexes with a single 2-cell . . .

Herbert Meyer Kamowitz, Compact operators of the form $u C_{\varphi}$

Matthew Liu and Billy E. Rhoades, Some properties of the Chebyshev method...

213

George Edgar Parker, Semigroups of continuous transformations and generating

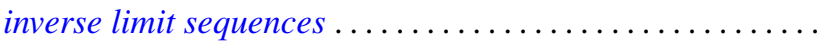

Samuel Murray Rankin, III, Oscillation results for a nonhomogeneous

equation ...

Martin Scharlemann, Transverse Whitehead triangulations ...

Gary Joseph Sherman, A lower bound for the number of conjugacy classes in a

finite nilpotent group

Richard Arthur Shoop, The Lebesgue constants for $\left(f, d_{n}\right)$-summability .

Stuart Jay Sidney, Functions which operate on the real part of a uniform

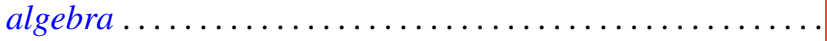

Tim Eden Traynor, The group-valued Lebesgue decomposition 